\title{
Acerca del estatuto problemático de las construcciones apositivas del tipo palabra clave, fecha límite
}

\section{The Problematic Status of the Appositive Constructions \\ of the Type palabra clave, fecha limite}

\author{
Petr Stehlík [stehlik@phil.muni.cz] \\ Universidad Masaryk, República Checa
}

\section{RESUMEN}

Este artículo se ocupa del estatuto problemático de las construcciones apositivas del tipo palabra clave, fecha límite, consideradas por algunos lingüistas españoles como compuestos sintagmáticos, fraseologismos o estructuras sintácticas libres. Según intentamos demostrar, las principales causas de la diversidad de opiniones al respecto radican tanto en la heterogeneidad de las construcciones nominales en cuestión, como en la insuficiente precisión de los criterios empleados para diferenciar los compuestos sintagmáticos de los fraseologismos.

\section{Palabras Clave}

Español; formación de palabras; composición sintagmática; construcciones apositivas

\begin{abstract}
This paper deals with the problematic status of the appositive constructions of the type palabra clave, fecha límite, considered by different Spanish linguists as syntagmatic compounds, phrasemes or free syntactic structures. As we try to demonstrate, the principal causes of this diversity of opinions lie both in the heterogeneity of the nominal constructions in question and in the insufficiently precise criteria of delimitation between syntagmatic compounds and phraseological units.
\end{abstract}

\section{KEYWORDS}

Spanish; word formation; syntagmatic compounding; appositive constructions

RECIBIDO 2019-06-28; ACEPTADO 2019-08-18 


\section{Introducción}

Las numerosas estructuras apositivas de tipo atributivo (p. ej. palabra clave, fecha límite) han recibido, en la lingüística española, al menos tres interpretaciones diferentes:

1) Para la mayoría de los morfólogos españoles (p. ej. Miranda 1994, Almela 1999, Varela 2005, Aguirre 2013), las construcciones arriba mencionadas son compuestos sintagmáticos binominales, al igual que, por ejemplo, hombre rana o pez espada. Esta postura se ve confirmada también en la NGLE (2009: 758): "Se forman productivamente compuestos de tipo atributivo con algunos nombres que se interpretan como exponentes de ciertas cualidades prototípicas"1.

2) Palabra clave, fecha límite y otros sintagmas similares pertenecen al inventario de las unidades fraseológicas. Así, Corpas Pastor (1996: 73) incluye las construcciones "formadas por dos sustantivos, donde uno de ellos modifica al otro" (p. ej. visita relámpago, hombre clave) entre las colocaciones con la estructura $\mathrm{N}+\mathrm{A}$. Según añade la autora, "que no son locuciones se comprueba por la posibilidad de sustitución paradigmática: limpieza/guerra/viaje relámpago, cuestión/decisión/reunión clave”. A este respecto, conviene observar que el mismo fenómeno es interpretado por los defensores de la naturaleza compositiva de las expresiones en cuestión como productividad neológica (véase más arriba).

3) Las construcciones $\mathrm{N}+\mathrm{N}$ de tipo atributivo no son, en realidad, ni compuestos sintagmáticos ni fraseologismos, sino sintagmas libres (falsos compuestos, pseudocompuestos). "Se trata de dos sintagmas nominales en aposición $\left(\mathrm{SN}_{1}+\mathrm{SN}_{2}\right)$, aunque estén con frecuencia constituidos únicamente por sus núcleos" (García-Page 2011: 128²); por ejemplo: (un) [[documento] notarial] [[clave] para comprender la historia $]^{3}$. Consecuente con esta interpretación, pero en marcado contraste con lo mencionado en los puntos 1 y 2, García-Page (2011: 157) afirma que "los pseudocompuestos no solo no forman paradigmas, sino que son incapaces de formar conjuntos unitarios".

A las tres posturas categóricas que acabamos de exponer puede añadirse todavía otra, más matizada, según la cual se dan construcciones apositivas con cierto grado de fijación al igual que otras completamente libres, así que hay que diferenciar. En este sentido, Alonso Ramos (2009: 270) advierte que "entre los llamados «seudocompuestos» por García-Page, sería necesario hacer un estudio detallado de cada caso. Algunos encajan como colocaciones, como noticia bomba [...]. Otros podrían tratarse como sintagmas libres".

En el presente artículo intentaremos señalar que tanto el concepto de compuesto sintagmático nominal como el de frasema nominal prototípico (locución) descansan sobre las mismas características fundamentales, lo que se refleja, a su vez, en la llamativa coincidencia de los rasgos de fijación semántica y morfosintáctica postulados para las dos categorías de unidades léxicas

1 A este particular grupo de compuestos pertenecen, según los académicos, p. ej. palabra clave, escena cumbre, cocinero estrella, negocio fantasma, fecha límite, conducta modelo, programa piloto, copia pirata (NGLE 2009: 758).

2 Véase también García-Page (2008: 105).

3 García-Page (2011: 142). 
pluriverbales ${ }^{4}$. Por ello, nuestro objetivo principal no consistirá en resolver si las expresiones del tipo palabra clave, fecha límite son compuestos o fraseologismos (del tipo que sea); nos enfocaremos, sobre todo, en examinar si estamos efectivamente ante sintagmas libres, tal como argumenta García-Page (2008 y 2011), o si es preciso "hacer un estudio detallado de cada caso", según afirma Alonso Ramos (2009: 270).

\section{Expresión de un concepto único vs. modificación del núcleo nominal}

Eugenio Bustos Gisbert, quien contribuyó significativamente al reconocimiento de las denominaciones pluriverbales como compuestos de pleno derecho (La composición nominal en español, 1986), basa la existencia del compuesto (sintagmático o no) en su unidad semántica y funcional, describiéndolo como "unidad plurilexemática de naturaleza léxica" (1986: 60). Para dar una definición más reciente, los compuestos sintagmáticos "forman una unidad solidaria y tienen un significado único, a pesar de que sus componentes se realicen como palabras separadas" (Varela 2005: 80).

Por otro lado, fue Julio Casares, fundador de los estudios de fraseología en español, el que definió la locución ${ }^{5}$ de una manera similar, pero no idéntica ${ }^{6}$, como "combinación estable de dos o más términos, que funciona como elemento oracional y cuyo sentido unitario consabido no se justifica, sin más, como una suma del significado normal de los componentes" (Casares 1950: 170). Dicha caracterización aparece reproducida o retomada en varias obras fraseológicas posteriores (p. ej. Zuluaga 1980, Corpas Pastor 1996), aunque ya Zuluaga estimó necesario hacer un deslinde entre las verdaderas locuciones y los compuestos regulares con función designativa o denominativa, señalando precisamente las locuciones denominativas geminadas de Casares (p. ej. falda pantalón, ciudad jardín, papel moneda) como "una prueba de la facilidad de confusión" al respecto (Zuluaga 1980: 143-144).

En vista de las dificultades delimitativas evidentes ${ }^{7}$, es lógico que también hayan aparecido propuestas de considerar todos los compuestos sintagmáticos como fraseologismos, según se observa,

4 Véanse, por ejemplo, Zuluaga (1980: 97-98), Bustos Gisbert (1986: 62), Corpas Pastor (1996: 23-24), Almela (1999: 137-138) o Alonso Ramos (2009: 250-253).

5 Casares (1950) no diferencia aún entre locuciones y colocaciones (según la tradición fraseológica, el concepto de colocación fue introducido por John R. Firth tan solo en 1957), pero tampoco Zuluaga (1980) incluye las colocaciones -bajo este nombre u otro- en su clasificación gradual de las UF (pág. 136). Se puede decir que prácticamente todos los estudios posteriores que consideran las colocaciones como una esfera fraseológica se fundamentan en (o quedan fuertemente influidos por) la concepción de Corpas Pastor, quien se ocupó detalladamente de la definición, delimitación y clasificación de las colocaciones en un capítulo particular de su Manual de fraseología española (1996: 53-87).

6 A pesar de que los compuestos sintagmáticos y las UF prototípicas (las locuciones) comparten los principales rasgos constitutivos, hay también una importante diferencia: mientras que los compuestos nominales conllevan "la formación de un concepto unitario que permite la designación de una realidad específica” (Val Álvaro 1999: 4765), es decir, funcionan como denominaciones primarias o normales, las locuciones nominales "se caracterizan por cumplir normalmente una función que denominamos de «atributividad». [...] Con ello se consigue caracterizar a un individuo (del que se dice que es un paño de lágrimas, que es utilizado como cabeza de turco, o que es un chivo expiatorio) o, más frecuentemente, una situación (juego de niños, cuento chino, pan comido)" (Montoro del Arco 2008: 137). Desde esta perspectiva, la expresión "significado único" que emplea Varela en su definición de los compuestos sintagmáticos no es equivalente al "sentido unitario" de las locuciones (véase la cita siguiente).

7 Ruiz Gurillo (2001: 36) describe la esfera de las locuciones como "una zona fluctuante entre los sintagmas libres y otros sintagmas, también estables, como los compuestos sintagmáticos y las colocaciones”. 
por ejemplo, en Corpas Pastor (1996) y Montoro del Arco (2008). Otra solución original que consigue obviar, al menos aparentemente, la necesidad de delimitar con precisión los dos grupos de unidades pluriverbales fue planteada por Mendívil Giró (2009), quien trata los compuestos sintagmáticos junto a los frasemas nominales bajo la etiqueta abarcativa palabras con estructura externa.

Ahora bien, aun reconociendo la imposibilidad de diferenciar claramente entre fraseologismos y compuestos sintagmáticos, de las primeras -y hasta hoy válidas- definiciones de estos dos tipos de unidades léxicas pluriverbales (Casares 1950: 170; Bustos Gisbert 1986: 60) se desprende que la propiedad básica que define los sintagmas nominales fijos frente a las estructuras sintácticas libres es la llamada unidad semántica (o sea, expresión de un concepto o significado unitario), responsable, en último término, de cualquier tipo de cohesión interna que presentan -eso sí, en diverso grado- los frasemas y los compuestos sintagmáticos nominales.

Por tanto, la cuestión absolutamente crucial es si los componentes de las construcciones del tipo palabra clave "constituyen una unidad semántica" (Gaviño Rodríguez - Rivas Zancarrón 2001: 99) y "ejercen, en conjunto, una función designativa, puesto que permiten aludir a un referente único" (Osorio Olave - Serra Sepúlveda 2012: 109), al igual que lo hacen los compuestos binominales prototípicos (hombre rana, pájaro mosca, etc.).

Desgraciadamente, la respuesta a esta cuestión no puede ser un simple sí o no ya que "el concepto de unidad semántica es ambiguo en sí mismo" y también porque son sobre todo los sintagmas que nos ocupan "los que impiden comprender la idea de que con estructuras endocéntricas del tipo traje de noche, café teatro, salón comedor, situación límite poseamos coherencia semántica, debido al hecho de que con ellas no nos referimos a nuevos conceptos u objetos, sino más bien a especializaciones o modificaciones de conceptos u objetos ya existentes" (Gaviño Rodríguez Rivas Zancarrón 2001: 106-107).

Otra razón de la confusión es que no estamos ante un grupo de formaciones homogéneo: hay expresiones binominales cuyo $\mathrm{N}_{2}$ es empleado con sentido figurado (p. ej. visita relámpago, noticia bomba), implícito (mujer objeto [sexual]) o completamente opaco (retrato robot), en tanto que la mayoría de las construcciones apositivas de tipo atributivo (asunto/pregunta clave, actor) deportista promesa, conducta/esposo modelo, etc.) tienen en común la transparencia o regularidad semántica del segundo nombre ${ }^{8}$ y su capacidad de dar lugar a series paradigmáticas.

En cualquier caso, creemos que ningún lingüista español podría explicar en qué exactamente consiste una mayor unidad semántica, conceptual o referencial de los "compuestos" nominales como asunto clave, deportista promesa, conducta modelo y muchos otros frente a los sintagmas libres asunto importante, deportista prometedor, conducta modélica/ejemplar, etc. (semánticamente equivalentes, pero con un modificador adjetivo). A nuestro parecer, tampoco existe un fundamento sólido para sostener que los ejemplos del primer grupo tengan un mayor grado de idiomaticidad ${ }^{9}$ que aquellos del segundo. No obstante, esto no implica automáticamente que todas las construcciones del tipo palabra/asunto/problema clave, fecha/esfuerzo/situación límite sean meros pseudocompuestos o sintagmas libres.

8 En este contexto, García-Page (2011: 163) habla del "significado constante de $\mathrm{N}_{2}$ y del valor monosémico de $\mathrm{N}_{1}$ cuando se combina con $\mathrm{N}_{2}$ ”. A diferencia de los pseudocompuestos, algunas denominaciones pluriverbales que funcionan como términos especiales pueden emplearse también con sentido figurado, es decir, como locuciones: p. ej. columna vertebral, denominador común, agujero negro.

9 Para más información sobre el grado de idiomaticidad de las construcciones apositivas, véase el apartado 3. 
Para ilustrar la complejidad del problema, pongamos por caso la formación prototípica palabra clave. En su uso más corriente, esta expresión significa 'palabra crucial, de especial importancia’ y pertenece, sin duda alguna, al mismo grupo de pseudocompuestos como asunto/hombre/pregunta clave $^{10}$. Por otra parte, hay que tomar en cuenta también la existencia de palabra clave como término de Informática, y ello en dos sentidos: "1. f. Inform. palabra significativa o informativa sobre el contenido de un documento, que se utiliza habitualmente para su localización y recuperación en una base de datos. 2. f. Inform. contraseña." (DLE 2018: en línea). En estos empleos, la construcción palabra clave de hecho tiene significado unitario y expresa un concepto único, por lo que puede clasificarse como compuesto sintagmático ( $\mathrm{y}$, dada la correspondencia exacta entre las dos acepciones especializadas de palabra clave y keyword, es un calco del inglés).

Examinemos ahora otro ejemplo ya clásico, a saber, fecha límite. A diferencia de palabra clave, esta construcción no aparece registrada en el DLE dentro de la entrada de $\mathrm{N}_{1}$ como expresión fija o locución (su contenido semántico resulta completamente transparente), y tampoco se trata de un calco $^{11}$. Sin embargo, hay un factor importante que considerar: el extranjerismo deadline ya se emplea en español como sinónimo -aunque menos frecuente y más bien informal- de fecha límite (p. ej.: el deadline para enviar tu propuesta / para el envío de los resúmenes / para entregar el artículo...). Desde esta perspectiva, no nos parece demasiado atrevido aventurar que la influencia del inglés como lengua internacional se ha extendido, al menos en algunos casos, también a lo que se percibe en otros idiomas como significado unitario o concepto único, con implicaciones interesantes para nuestro tema (semánticamente, fecha límite podría ser un compuesto, a pesar de no comportarse como un sintagma completamente fijo ${ }^{12}$ y no estar recogido en los diccionarios representativos actuales).

En su artículo sobre las construcciones apositivas de tipo atributivo, García-Page (2011: 152) cuestiona, con razón, el supuesto de que "la traducción a otra lengua pudiera servir para corroborar la naturaleza morfológica del compuesto, en la medida en que permite revelar el distinto proceso nominativo que utilizan las lenguas para designar una realidad”, pues, según él, "es también comprobable que ciertos pseudocompuestos en una lengua son traducibles a otra por una palabra, como es el caso de fecha límite = deadline, por lo que el criterio de la traducción no es del todo fiable". Aunque, en principio, compartimos la opinión del autor sobre la fiabilidad del criterio mencionado (la segmentación o estructuración del continuum de la realidad extralingüística a través de las lenguas naturales no tiene por qué ser universal, de modo que la disponibilidad de un término univerbal en un idioma no es prueba suficiente para clasificar, sin más, su equivalente pluriverbal en otra lengua como compuesto sintagmático ${ }^{13}$, creemos que la argumentación de García-Page resulta un poco circular. Habría que demostrar primero que fecha límite y palabra clave son realmente meros pseudocompuestos; algo que, como se ha visto, sería difícil de sostener. Por otro lado, partiendo solo del criterio de la traducción, la ecuación deadline (ingl., compuesto gráfico) = fecha límite (esp., compuesto sintagmático) debe ser rechazada como infundada y simplista.

10 Como explica bien García-Page (2011: 149), “en los pseudocompuestos, $\mathrm{N}_{1}$ tiene independencia semántica y referencial (presenta todas las propiedades referenciales que le corresponden como sintagma)".

11 La traducción literal de deadline sería "línea muerta".

12 Véase el apartado 4.1.

13 Por cierto, dicho criterio fue criticado también en el ámbito de la fraseología. En palabras de Zuluaga, "pretender identificar fenómenos de una lengua según la traducibilidad es querer juzgarla según la forma de otra lengua” (1980: 61). 


\section{Grado de idiomaticidad}

En el apartado 2 hemos señalado que la mayoría de las estructuras apositivas de tipo atributivo probablemente no son compuestos sintagmáticos, pues no cumplen con la condición básica de tener un significado unitario y un referente único (que es la característica definitoria del compuesto). Ahora nos queda por ver si los sintagmas como asunto/problema clave, esfuerzo/situación límite, actor/deportista promesa, conducta/esposo modelo caben en la categoría de fraseologismos, delimitada de una manera menos estricta ${ }^{14}$ que la de los compuestos sintagmáticos en la morfología.

Admitiendo por un momento que las construcciones $\mathrm{N}+\mathrm{N}$ que nos ocupan sean realmente frasemas, en el caso de los sintagmas apositivos del tipo asunto/problema clave no podría tratarse (al menos según la clasificación tradicional de las UF) de locuciones nominales, ya que el primer nombre, o sea, el núcleo, es utilizado siempre con sentido literal y "tiene independencia semántica y referencial” (García-Page 2011: 149). Recordemos, sin embargo, que Corpas Pastor sitúa las construcciones binominales limpieza/guerra/viaje/visita relámpago, cuestión/decisión/hombre/ reunión clave, etc. en la esfera de las colocaciones, definidas por ella (1996: 66) como "unidades fraseológicas formadas por dos unidades léxicas en relación sintáctica [...] que, debido a su fijación en la norma, presentan restricciones de combinación establecidas por el uso, generalmente de base semántica: el colocado autónomo semánticamente (la base) no sólo determina la elección del colocativo, sino que, además, selecciona en éste una acepción especial, frecuentemente de carácter abstracto o figurativo"15.

Desde este punto de vista, el significado constante y transparente del modificador yuxtapuesto $\left(\mathrm{N}_{2}\right)$ en las construcciones de tipo atributivo puede considerarse "una acepción especial" del nombre respectivo (clave, límite, promesa, modelo, etc.), indicada en el DLE -aunque no sistemáticamente- como típica de su uso en aposición. Sin embargo, dada la notoria subjetividad de cualquier análisis semántico, igualmente sería posible afirmar que, por ejemplo, límite en fecha límite y situación límite no se comporta como un elemento semánticamente constante porque adquiere, en las formaciones respectivas, significados distintos: fecha límite ('de cierre, final'), situación límite ('crítica, extrema').

También Alonso Ramos (2009: 254-256), al igual que Corpas Pastor, establece la violación de la selección irrestricta como propiedad fundamental y mínima que distingue las colocaciones ( sintagmas no libres $=$ frasemas) de las combinaciones libres, pero al argumentar a favor de la necesidad de un análisis caso por caso de los pseudocompuestos de García-Page (Alonso Ramos 2009: 270 $)^{16}$, la autora adopta un criterio mucho más estricto y, sobre todo, solo facultativo en las colocaciones: se trata de la opacidad o transparencia del modificador yuxtapuesto ${ }^{17}$. Por otro

14 Nos referimos sobre todo a las colocaciones (véase más adelante).

15 Desgraciadamente, el espacio limitado del presente artículo no nos permite profundizar en la compleja problemática de las colocaciones. Por ello, remitimos al lector sobre todo a Koike (2001), uno de los trabajos más detallados y citados sobre le tema. De los artículos que cuestionan la utilidad del concepto de colocación en el ámbito de la fraseología, véanse, p. ej., Sánchez Rufat (2010) y Osorio Olave - Serra Sepúlveda (2012).

16 De este modo, Alonso Ramos se distancia, al menos implícitamente, de la posición de Corpas Pastor (1996: 73), quien clasifica las construcciones $\mathrm{N}+\mathrm{N}$ de tipo atributivo como colocaciones.

17 “En una colocación, la UL B puede significar 'B' o 'C'. Lo pertinente es que como UL es seleccionada en función de A" (Alonso Ramos 2009: 256). 
lado, hay que reconocer que Alonso Ramos no se contenta con determinar, de una manera "impresionista”, si el nombre en aposición tiene un sentido más o menos figurado o si oculta algún sema implícito. El problema es que tampoco el método lexicográfico utilizado por ella -y que consiste en otorgar el estatuto de colocación solo a aquellas construcciones binominales que aparezcan registradas y explicadas en la entrada de $\mathrm{N}_{1}$ - arroja resultados satisfactorios, como se observará a continuación.

Para Alonso Ramos (2009: 270), noticia bomba (a diferencia de mujer objeto o visita relámpago) es una colocación porque "en la entrada de la UL noticia es necesario indicar cómo se expresa el significado 'que causa sensación”'. Curiosamente, la versión del DLE que ya pudo consultar la autora (la 22. ${ }^{a}$ edición de 2001) también recoge la construcción mujer objeto ${ }^{18}$; pero, en este caso, Alonso Ramos abandona el criterio lexicográfico mantenido en las líneas anteriores y pasa a afirmar que "si establecemos que existe un nombre objeto con el significado 'considerado solo desde un punto de vista sexual', la combinación mujer/hombre objeto es un sintagma libre"19. En lo que se refiere al uso figurado de relámpago en aposición, este aparece indicado directamente en la entrada del modificador ${ }^{20}$, es decir, igual que el significado figurativo de algunos adjetivos que forman colocaciones prototípicas (p. ej. error garrafal, momento crucial). Por tanto, podemos suponer que el diferente tratamiento de la expresión mujer objeto frente a visita/viaje/ataque ... relámpago no tiene nada que ver con su condición de sintagma libre o colocación, sino que se debe a razones de economía lexicográfica: simplemente hay demasiadas combinaciones de $\mathrm{N}_{1}+$ relámpago ${ }^{21}$ como para registrarlas, por separado, dentro de la entrada de $\mathrm{N}_{1}$.

\section{Grado de fijación formal}

Las propiedades que conforman la llamada fijación formal o material de las unidades léxicas pluriverbales fueron descritas de una manera más o menos detallada por varios lingüistas enfocados al estudio de los compuestos sintagmáticos y/o los fraseologismos ${ }^{22}$, así que -en vista del tema específico del presente artículo- no consideramos necesario reproducirlas aquí en su totalidad y nos detendremos, a continuación, solo en dos rasgos que presentan especial interés teórico y que, a la vez, ilustran las limitaciones de las pruebas de fijación formal. Se trata, concretamente, de las siguientes características: 1) la imposibilidad de modificación parcial (interna) del sintagma fijo; 2) la imposibilidad de elisión o sustitución de sus componentes ${ }^{23}$. Conviene advertir, al igual que

18 "La que es valorada exclusivamente por su belleza o atractivo sexual” (DLE 2001: en línea); "mujer que es valorada exclusivamente por su belleza o atractivo sexual" (DLE 2018: en línea).

19 Baste añadir que el DLE no hace mención alguna, en la entrada de la UL objeto, al significado específico de este sustantivo en aposición.

20 "U. en aposición para denotar la rapidez, carácter repentino o brevedad de algo. Guerra relámpago. Ministerio relámpago." (DLE 2001 y 2018: en línea).

21 Por cierto, de la misma manera se indica en el DLE (2018) el significado específico -y más transparente que en el caso de relámpago- de varios otros nombres utilizados en aposición, p. ej. de clave, límite o modelo.

22 Véase la nota al pie 4.

23 Esta selección no agota, ni mucho menos, todos los rasgos de fijación formal de las unidades léxicas pluriverbales. Para un análisis más completo y detallado, véase García-Page (2011). 
en los apartados anteriores, que ninguno de estos criterios puede servir para demostrar que las construcciones binominales en cuestión son sintagmas libres o, al contrario, expresiones fijas.

\subsection{Imposibilidad de modificación parcial del sintagma fijo}

Como explica Bustos Gisbert (1986: 35), "las determinaciones parciales o rompen la motivación del compuesto o dan lugar a contradicciones semánticas, por esa interpretación literal del grupo sintáctico correspondiente"; p. ej.: lengua de gato > *una lengua sabrosa de gato; piel roja > *una piel muy roja.

Aplicada esta prueba a las construcciones apositivas del tipo problema clave, la modificación del sustantivo nuclear o adyacente es posible sin que se pierda o quede afectado el significado básico de la expresión pluriverbal, como se ve en los siguientes ejemplos: un documento notarial clave, un hombre modelo de buena educación (García-Page 2011: 141-142), un momento especialmente clave, conclusiones éticamente límites (Rainer 1993: 252). Está claro que la posibilidad de una expansión adverbial de $\mathrm{N}_{2}$ depende, asimismo, de si el nombre con función adjetiva expresa un significado calificativo/valorativo (p. ej. clave, cumbre, estrella, promesa, relámpago, etc.) o relacional $\left(\right.$ objeto, robot $\left.{ }^{24}\right)$. También las formaciones que denotan o pueden denotar un concepto único, es decir, palabra clave y fecha límite ${ }^{25}$, experimentan modificaciones parciales (p. ej. una palabra injuriosa clave, la fecha de matrícula límite; García-Page 2008: 106), pero aquí conviene hacer algunas precisiones importantes. En lo que se refiere a palabra clave, creemos necesario diferenciar entre su uso como término de Informática (con los significados de 'palabra de búsqueda' y 'contraseña'), probablemente sin determinaciones parciales factibles, o como una combinación de palabras libre (equivalente a palabra importante/crucial y comparable a otras construcciones apositivas con clave, p. ej. cuestión/decisión/problema clave), la cual sí puede ser modificada de manera parcial. La construcción fecha límite es especialmente interesante ya que demuestra que el grado de fijación formal de una expresión pluriverbal no tiene que estar en relación directa con su unidad semántica y su empleo como término (en este caso, dentro del ámbito administrativo).

\subsection{Imposibilidad de elisión o sustitución de los componentes}

Otro aspecto relevante de la cohesión formal es la imposibilidad de elidir o sustituir cualquiera de los elementos de una estructura sintáctica lexicalizada.

La prueba de elisión puede resultar útil para determinar el grado de idiomaticidad de los diferentes tipos de fraseologismos, pero hay que tomar en consideración que "en el momento en el que un SN adquiere valor denominativo, automáticamente pierde composicionalidad" (Mendívil Giró 2009: 101). Por consiguiente, al adoptar a priori la postura de que las construcciones del tipo problema clave son compuestos sintagmáticos (tal como se sostiene en la NGLE y en la mayoría de

24 Nos referimos concretamente a las expresiones mujer objeto y retrato robot, que presentan un grado de cohesión semántica y morfosintáctica notablemente más alto que las construcciones del tipo problema clave.

Véase el apartado 2. 
los trabajos sobre formación de palabras), dicha prueba se vuelve insignificante porque la omisión de $\mathrm{N}_{2}$ destruiría "la imagen única" que, supuestamente, evocan estas expresiones (véase Bartoš 1999: 55).

$\mathrm{Si}$, en cambio, asumimos que solo determinados sintagmas binominales de tipo atributivo son "verdaderos" compuestos con significado unitario (como palabra clave en el ámbito de Informática), se puede argumentar que el segundo nombre en decisión clave, niño prodigio, deportista promesa, etc. no conforma, en combinación con el núcleo, ningún concepto único, sino que simplemente modifica el significado básico de $\mathrm{N}_{1}$, al igual que su equivalente adjetivo en los sintagmas nominales libres una decisión crucial, un niño prodigioso o un deportista prometedor.

Sin embargo, hay todavía otro criterio que concierne a la fijación del inventario de los componentes del sintagma lexicalizado: se trata de la sustitución -hipotética o factible- de alguno de sus elementos por un sinónimo. Al realizar esta prueba, se verá afectado el significado de todos los fraseologismos y compuestos nominales en los que la palabra sustituida no tenga sentido básico o literal (p. ej.: negocio redondo $>{ }^{*}$ negocio circular), pero es interesante observar que tampoco las expresiones del tipo conducta modelo, cuestión clave o situación límite se comportan al respecto como sintagmas libres. Hablando más concretamente, mientras que el elemento nuclear de los ejemplos arriba citados puede sustituirse sin problema por un sinónimo (conducta modelo $>$ comportamiento modelo; cuestión clave > pregunta clave; situación límite > condición/circunstancia límite), es imposible efectuar lo mismo con el segundo nombre de la estructura apositiva (situación límite $>{ }^{*}$ situación frontera/término; conducta modelo $>{ }^{*}$ conducta ejemplo/prototipo ${ }^{26}$ ). Parece, por tanto, que el miembro más fijo o estable de las construcciones en cuestión no es el núcleo sintáctico $\left(\mathrm{N}_{1}\right)$, sino el modificador (clave, límite, etc.). No obstante, en lugar de interpretar este hecho como una violación de la llamada selección irrestricta, la cual, según Alonso Ramos (2009: 255), fundamenta la diferencia entre los sintagmas libres y los sintagmas fraseológicos ${ }^{27}$, consideramos más lógico adscribirlo al simple hecho de que los sustantivos clave, modelo, promesa, prodigio, estrella, etc. suponen ya de por sí un recurso alternativo al uso de adjetivos como importante, ejemplar, prometedor, prodigioso, destacado, etc., lo que, a su vez, ofrece una explicación al inventario limitado o cerrado de nombres que pueden funcionar como modificadores cuasiadjetivales.

\section{Conclusiones}

1) Dada la heterogeneidad de los sintagmas nominales incluidos en el grupo de construcciones apositivas que nos ocupa, ninguna de las tres interpretaciones categóricas presentadas al comienzo resulta completamente correcta o falsa. Aun así, coincidimos con García-Page (2008 y 2011) en que la mayoría de las formaciones en cuestión -pero no todas- son meros pseudocompuestos,

26 Como contraejemplo podemos mencionar el modificador apositivo promesa: niño/deportista promesa > niño/ deportista talento. En cuanto a los sintagmas apositivos con clave, en algunos de ellos podría utilizarse como sinónimo aproximativo el sustantivo base (pregunta/cuestión clave > pregunta/cuestión base), pero esta sustitución no resulta posible en el caso del sintagma dificultad clave (dificultad base = dificultad mínima).

27 Ahora bien, como observan Osorio Olave y Serra Sepúlveda (2012: 106-107), "si tanto los sintagmas libres como las colocaciones están compuestos por un núcleo léxico y un complemento, entonces la direccionalidad en que se produce la selección es también la misma, a saber, del colocativo a la base [...]. En efecto, todo predicado ejerce ciertas restricciones de selección sobre los argumentos que selecciona”. 
sobre todo porque no desempeñan la función denominativa propia de los compuestos sintagmáticos (véase la nota al pie de página 6).

2) Un análisis caso por caso es imprescindible (en ello estamos de acuerdo con Alonso Ramos); sin embargo, a menos que se establezcan criterios más fiables para delimitar los ámbitos de la morfología léxica, la fraseología y la sintaxis, la cuestión de si estamos ante compuestos sintagmáticos, fraseologismos o sintagmas libres es, hasta cierto punto, académica.

3) Aunque se han propuesto varias pruebas de cohesión semántica y formal para diferenciar los sintagmas fijos de las combinaciones libres de palabras, el carácter gradual de los rasgos observados, la precariedad de algunos criterios (p. ej. el lexicográfico, comentado en los apartados 2 y 3) y la existencia de numerosos contraejemplos hacen imposible obtener resultados claros y convincentes que permitan esclarecer, de una vez, el estatuto de las construcciones examinadas. A estos problemas particulares se suma la llamativa vaguedad del concepto de colocación en la teoría fraseológica, debido a la cual casi resulta más fácil afirmar, sin necesidad de argumentación alguna, que cualquier construcción $\mathrm{N}+\mathrm{N}$ de tipo atributivo es una colocación (y, por consiguiente, un sintagma con "cierta fijación interna" o "no libre" 28 ) que demostrar lo contrario con pruebas irrefutables. También por ello -además de por el hecho indiscutible de que las locuciones nominales tienen más propiedades en común con los compuestos sintagmáticos que con las colocaciones-, nos alineamos con los lingüistas que abogan por una concepción estrecha de la fraseología, es decir, sin las colocaciones dentro del ámbito de las UF (p. ej. García-Page 2008, Osorio Olave - Serra Sepúlveda 2012).

\section{Referencias bibliográficas}

Aguirre, C. (2013). Manual de morfología del español. Barcelona: Castalia.

Almela Pérez, R. (1999). Procedimientos de formación de palabras en español. Barcelona: Ariel.

Alonso Ramos, M. (2009). Delimitando la intersección entre composición y fraseología. LEA, XXXI (2), 243-275.

. (2012). Sobre por qué un grupo de palabras puede ser una sola palabra sin ser paradójico. In E. T. Montoro del Arco (Ed.), Neología y creatividad lingüistica (pp. 115-136). Valencia: Universitat deValència. Bartoš, L. (1999). En torno a las formaciones binominales yuxtapuestas en español. Études romanes de Brno, L20, 49-58.

Bustos Gisbert, E. (1986). La composición nominal en español. Salamanca: Ediciones de la Universidad de Salamanca.

Casares Sánchez, J. (1950). Introducción a la lexicografía moderna. Madrid: CSIC.

Corpas Pastor, G. (1996). Manual de fraseología española. Madrid: Gredos.

Firth, J. R. (1957). Modes of Meaning. In J. R. Firth: Papers in Linguistics 1934-1951 (pp. 190-215). London: Oxford University Press.

García-Page Sánchez, M. (2008). Introducción a la fraseología española: Estudio de las locuciones. Barcelona: Anthropos. 
. (2011). Hombre clave, hombre rana, ¿un mismo fenómeno? Verba, 38, 127-170.

Gaviño Rodríguez, V.; \& Rivas Zancarrón, M. (2001). Composición sintagmática vs. sintagmas libres. Criterios para su delimitación. In M. González Pereira, \& M. Souto Gómez (Eds.), Cuestiones conceptuales y metodológicas de la lingüística (pp. 99-108). Santiago de Compostela: Universidad de Santiago de Compostela.

Koike, K. (2001). Colocaciones léxicas en el español actual: estudio formal y léxico-semántico. Alcalá de Henares: Universidad de Alcalá y Takushoku University.

Mendívil Giró, J. L. (2009). Palabras con estructura externa. In E. de Miguel Aparicio (Ed.), Panorama de la lexicología (pp. 83-113). Barcelona: Ariel.

Miranda, J. A. (1994). La formación de palabras en español. Salamanca: Ediciones Colegio de España.

Montoro del Arco, E. T. (2008). Relaciones entre Morfología y Fraseología: las formaciones nominales pluriverbales. In R. Almela Pérez, \& E. T. Montoro del Arco (Eds.), Neologismo y morfología (pp. 121-146). Murcia: Universidad de Murcia.

Osorio Olave, G.; \& Serra Sepúlveda, S. (2012). Colocaciones, compuestos sintagmáticos y locuciones nominales: hacia un intento de delimitación conceptual. Lenguas Modernas, 39, 103-116.

Rainer, F. (1993). Spanische Wortbildungslehre. Tübingen: Max Niemeyer Verlag.

[DLE 2001]: Real Academia Española. (2001). Diccionario de la lengua española, 22. a ed. Madrid: Espasa Calpe. <https://www.rae.es/recursos/diccionarios/diccionarios-anteriores-1726-2001/diccionario-de-la-lengua-espanola-2001>

[DLE 2018]: - (2018). Diccionario de la lengua española. Edición del Tricentenario. Actualización 2018. <https://dle.rae.es>

[NGLE 2009]: Real Academia Española y Asociación de Academias de la Lengua Española. (2009). Nueva gramática de la lengua española. Madrid: Espasa Libros.

Ruiz Gurillo, L. (2001). Las locuciones en español actual. Madrid: Arco/Libros.

Sánchez Rufat, A. (2010). Apuntes sobre las combinaciones léxicas y el concepto de colocación. Anuario de Estudios Filológicos, XXXIII, 291-306.

Val Álvaro, J. F. (1999). La composición. In I. Bosque, \& V. Demonte (Eds.), Gramática Descriptiva de la Lengua Española, Vol. 3 (pp. 4757-4841). Madrid: Espasa Calpe.

Varela Ortega, S. (2005). Morfología léxica: La formación de palabras. Madrid: Gredos.

Zuluaga Ospina, A. (1980). Introducción al estudio de las expresiones fijas. Frankfurt: Peter D. Lang. 
